\title{
Effects of individual and multiple fatty acids (palmitate, oleate and docosahaexenoic acid) on cell viability and lipid metabolism in LO2 human liver cells
}

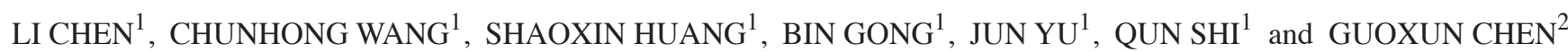 \\ ${ }^{1}$ Department of Toxicology, School of Public Health, Wuhan University, Wuhan, Hubei 430071, P.R. China; \\ ${ }^{2}$ Department of Nutrition, The University of Tennessee at Knoxville, Knoxville, TN 37996, USA
}

Received December 3, 2013; Accepted May 9, 2014

DOI: $10.3892 / \mathrm{mmr} .2014 .2579$

\begin{abstract}
This study was designed to investigate the direct effects of fatty acids (FAs) on the cell viability and the expression levels of genes involved in lipid metabolism in LO2 human liver cells. Palmitate (PA), oleate (OA) and docosahaexenoic acid (DHA) were used to represent saturated, mono-unsaturated and polyunsaturated FAs, respectively. At concentrations of $\leq 3.2 \mu \mathrm{g} / \mathrm{ml}$, treatment with single FAs increased the viability of the LO2 cells. At FA concentrations of $>3.2 \mu \mathrm{g} / \mathrm{ml}$, cell viability following OA treatment was increased, but PA or DHA treatment at these concentrations reduced cell viability. Administration of mixtures of these FAs in three ratios (PA:OA:DHA = 1:2:1, 1:1:1 and 1:1:2, respectively) increased the cell viability compared with the control group. The intracellular triglyceride (TG) levels following all types of treatment were significantly increased and the accumulation of TGs was markedly increased with high doses of DHA. In addition, peroxisome proliferator-activated receptor- $\gamma$ was significantly upregulated in all groups, with the exception of the 1:1:1 group at $3.2 \mu \mathrm{g} / \mathrm{ml}$ and the 1:1:2 group at
\end{abstract}

Correspondence to: Dr Chunhong Wang, Department of Toxicology, School of Public Health, Wuhan University, 115 Donghu Road, Wuhan, Hubei 430071, P.R. China

E-mail: wchunhong027@whu.edu.cn

Dr Guoxun Chen, Department of Nutrition, The University of Tennessee at Knoxville, Knoxville, TN 37996, USA

E-mail: gchen6@utk.edu

Abbreviations: FAs, fatty acids; SFA, saturated fatty acid; MUFA, monounsaturated fatty acid; PUFA, polyunsaturated fatty acid; PA, palmitic acid; OA, oleic acid; DHA, docosahaexenoic acid; AST, aspartate transaminase; TG, triglyceride; PPAR- $\gamma$, peroxisome proliferator-activated receptor $\gamma ; \mathrm{LXR} \alpha$, liver $\mathrm{X}$ receptors; SREBP-1c, sterol regulatory element binding protein 1c; apoC-I, apolipoprotein C-I

Key words: LO2 liver cells, fatty acids, cell viability, lipid metabolism
$12.8 \mu \mathrm{g} / \mathrm{ml}$. The expression levels of sterol regulatory-element binding protein-1c, liver $\mathrm{X}$ receptor $\alpha$ and apolipoprotein $\mathrm{C}-\mathrm{I}$ were significantly reduced in all groups with the exception of the DHA-treated group and the 1:2:1 groups at 3.2 and $12.8 \mu \mathrm{g} / \mathrm{ml}$. In conclusion, these results indicate that the type, concentration and mixture ratios of FAs are all important in determining the cell viability and lipid metabolism-related gene expression in LO2 hepatocytes.

\section{Introduction}

As a predominant source of energy and a crucial component of biological cell membranes, fat is an important macronutrient for humans and other mammals. The level of fat intake is positively correlated with the average serum cholesterol and the mortality rate due to coronary heart disease (1). Fatty acids (FAs) are classified as saturated, monounsaturated and polyunsaturated, and the biological functions of the FAs depend on molecular structure and cellular accumulation. Normally, FAs absorbed in the liver are esterified to triglycerides (TGs) for transportation to extrahepatic tissues by lipoproteins, and are oxidized via $\beta$-oxidation in the mitochondria or peroxisomes. With an increase in nutrient intake, the hepatic FA level is significantly increased, which may result in mitochondrial oxidation of FAs and oxidative stress in the liver $(2,3)$, with subsequent development of metabolic disease. For example, diabetes is commonly associated with changes in hepatic glucose and lipid metabolism (4), which may be partly attributed to the altered expression levels of hepatic genes involved in glucose and lipid metabolism (5).

As precursors of the ligands that bind to nuclear receptors $(6,7)$, FAs are key in the regulation of intracellular signaling pathways. Highly unsaturated fatty acids (HUFAs; 20- and 22-carbon omega- 6 or omega- 3 polyenoic fatty acids) have been reported to inhibit the transcription of glycolytic and lipogenic genes through two types of HUFA regulatory response regions (HUFA-RR) (7). One region overlaps with the insulin response element (IRE), while the other co-localizes with the carbohydrate response element. The HUFA-RR/IRE contains recognition sequences of sterol regulatory-element binding protein 1c $(S R E B P-1 c)$. As a result, HUFAs inhibit the activity of promoters containing the HUFA-RR/IRE by 
reducing the levels of $S R E B P-1 c$ associated with the respective recognition sequences. SREBP-lc and peroxisome proliferator-activated receptors (PPARs) regulate multiple signaling pathways involved in hepatic carbohydrate and lipid metabolism $(8,9)$. Polyunsaturated fatty acids (PUFAs) activate PPARs by direct binding, which results in the induction of hepatic FA oxidation and thus the inhibition of hepatic FA synthesis by suppressing SREBP-1c gene transcription and enhancing SREBP-1c mRNA degradation. In murine models of obesity and type 2 diabetes mellitus, PPAR- $\gamma$ mRNA and protein levels were upregulated in the liver (10). The activation of liver X receptors (LXRs), members of the nuclear receptor family, inhibits the synthesis of cholesterol (11) in the liver and the absorption of cholesterol in the intestinal tract (12). Apolipoproteins (apo)C-I and E synthesized by the liver are predominant plasma proteins involved in the transport of cholesterol and TGs. Overactivated apoC-I may prevent the development of insulin resistance (13). A PPAR receptor response element is located in the control region of the apoE/C-I gene cluster (14). However, the effect of exogenous FAs on the expression levels of the apoC-I gene is not clear.

Although a number of previous studies have investigated the effects of dietary fat on the expression levels of hepatic genes involved in lipid metabolism (15-17), the studies have mainly focused on high-PUFA. However, dietary fat is a mixture of saturated, monounsaturated and polyunsaturated FAs. Reports regarding the effects of FA mixtures containing three types of FA on the expression levels of genes involved in hepatic lipid metabolism are limited. In the present study, palmitic acid (PA, C16:0), oleic acid (OA, C18:1) and docosahaexenoic acid (DHA, C22:6) were selected to represent saturated, mono-unsaturated and poly-unsaturated FAs, respectively. According to a previous study (18), LO2 cells can be used to establish an in vitro model of hepatocyte steatosis. Using treatment with single or multiple FAs at different concentrations, the cytotoxicity and effects of the FAs on the expression levels of genes involved in lipid metabolism in human hepatic LO2 cells were investigated in order to provide an improved understanding of the influence of FA composition in dietary fats on lipid metabolism.

\section{Materials and methods}

Cell culture and treatment with FAs. $\mathrm{LO} 2$ cells were obtained from Tongji Medical College (Wuhan, China) and were cultured in RPMI-1640 media supplemented with $10 \%$ fetal bovine serum and $1 \%$ penicillin/streptomycin at $37^{\circ} \mathrm{C}$ in a humidified incubator with $5 \% \mathrm{CO}_{2}$. When the cells reached $75 \%$ confluence, serum-free medium with different concentrations of FAs was added into the culture for $24 \mathrm{~h}$. The concentrations of PA, OA and DHA used were $0,0.4,0.8$, 1.6, 3.2, 6.4 and $12.8 \mu \mathrm{g} / \mathrm{ml}$. PA, OA and DHA were obtained from Sigma (St. Louis, MO, USA) and were dissolved in absolute ethyl alcohol (stock solution, $5 \mathrm{mg} / \mathrm{ml}$ ). Three ratios (mass-to-volume ratio) of PA, OA and DHA were selected, 1:2:1, 1:1:1 and 1:1:2, according to the SFA/MUFA/PUFA ratio (1:1.7:1.2) of the average Chinese diet (19). As determined by the cytotoxicity of each FA, the concentrations of mixed FAs were selected to be 3.2 and $12.8 \mathrm{~g} / \mathrm{ml}$.
Cell viability. The effect of FAs on the viability of $\mathrm{LO} 2$ cells was assessed by a 3-(4, 5-dimethylthiazol-2-yl)-2, 5-diphenyl tetrazolium bromide (MTT; Amresco, Solon, OH, USA) assay. LO2 cells were seeded in 96 well plates at $1 \times 10^{4}$ cells/well. After $24 \mathrm{~h}$ FA treatment, $20 \mu \mathrm{l}$ MTT solution $(5 \mathrm{mg} / \mathrm{ml}$, OH, USA) was added to each well and the cells were incubated for $4 \mathrm{~h}$ at $37^{\circ} \mathrm{C}$. A volume of $100 \mathrm{ml}$ dimethyl sulfoxide (Amresco) was then added to each well to dissolve the formazan salts and the optical absorbance at $490 \mathrm{~nm}$ was determined via a microplate reader (BioTek Instruments, Inc., Winooski, VT, USA). The viability is shown as a percentage of the corresponding control.

Aspartate transaminase (AST) release assay. $\mathrm{LO} 2$ cells were cultured in 12-well plates at $2 \times 10^{5}$ cells/well. Following treatment with FAs for $24 \mathrm{~h}, 2 \mathrm{ml}$ medium was collected and spun at $1,000 \mathrm{x} \mathrm{g}$ for $5 \mathrm{~min}$ at $4^{\circ} \mathrm{C}$. Thus, AST was released from the destroyed LO2 cells. The supernatant was transferred to a fresh tube and stored at $4^{\circ} \mathrm{C}$ for subsequent measurements. The activities of AST in the media were assessed using an AST assay kit (Nanjing Jiancheng Bioengineering Institute, Nanjing, China) following the manufacturer's instructions. The AST activity was presented as U/l. The higher the AST activity, the lower the cell viability.

Measurement of intracellular TG. LO2 cells were cultured in 12 -well plates at $2 \times 10^{5}$ cells/well. Following treatment with the FAs for $24 \mathrm{~h}$, the cells were washed with ice-cold phosphate-buffered saline and dissolved in lysis buffer $[50 \mathrm{mM}$ Tris ( $\mathrm{pH}$ 7.4), $150 \mathrm{mM} \mathrm{NaCl}, 1 \%$ Triton $\mathrm{X}-100,1 \%$ sodium deoxycholate, $0.1 \%$ SDS, $1 \mathrm{mM}$ sodium orthovanadate, $50 \mathrm{mM}$ sodium fluoride, $1 \mathrm{mM}$ EDTA and $20 \mu \mathrm{g} / \mathrm{ml}$ leupeptin]. The lysates were spun at $12,000 \mathrm{x}$ g for $5 \mathrm{~min}$ at $4^{\circ} \mathrm{C}$. The TG concentration in the supernatant was detected using a TG assay kit (Jiancheng Bioengineering Institute, Nanjing, Jiangsu, China) following the manufacturer's instructions and then normalized to total protein content.

Expression levels of $m R N A$. After $6 \mathrm{~h}$ FA treatment, the LO2 cells were collected and total RNA was isolated using Trizol reagent (Life Technologies Corporation, Grand Island, NY, USA) following the manufacturer's instructions. The concentration [absorbance at $260 \mathrm{~nm}$, i.e. optical density (OD)260 and purity (OD260/OD280)] of the RNA samples were assessed using a DU Series 700 UV/Vis Scanning Spectrophotometer (Beckman Coulter, Miami, FL, USA). The concentration of the isolated RNA was adjusted to $1 \mathrm{mg} / \mathrm{ml}$, stored at $-80^{\circ} \mathrm{C}$ and was thawed once. Single-strand cDNA was prepared from $1 \mathrm{mg}$ RNA using a reverse transcription-polymerase chain reaction (RT-PCR) assay kit (Life Technologies Corporation) according to the manufacturer's instructions.

The expression levels of PPAR- $\gamma, L X R \alpha, S R E B P-1 c$, apoC-I and GAPDH mRNA were determined by RT-PCR. All primers and the product sizes for the genes analyzed in the present study are shown in Table I. At the end of RT-PCR, an extension step was performed at $72^{\circ} \mathrm{C}$ for 5 min and the products were stored at $4^{\circ} \mathrm{C}$ for further analysis. Each PCR sample was separated on a $2 \%$ agarose gel. The integrated optical density of each gene on the gel was analyzed using G:BOX Chemi XR5 (Syngene, Cambridge, UK). The gene 
Table I. Primer sequences of the corresponding genes.

\begin{tabular}{|c|c|c|c|}
\hline Gene & Primer sequence 5'-3' & $\begin{array}{l}\text { Amplified fragment } \\
\text { length (bp) }\end{array}$ & $\begin{array}{c}\text { GeneBank accession } \\
\text { number }\end{array}$ \\
\hline$P P A R-\gamma$ & $\begin{array}{l}\text { F: GCTGGCCTCCTTGATGAATA } \\
\text { R: TTGGGCTCCATAAAGTCACC }\end{array}$ & 114 & NM_138711 \\
\hline$L X R \alpha$ & $\begin{array}{l}\text { F: CGCACTACATCTGCCACAGT } \\
\text { R: TCAGGCGGATCTGTTCTTCT }\end{array}$ & 141 & NM_001251935 \\
\hline$S R E B P-1 c$ & $\begin{array}{l}\text { F: CCTATTTGACCCACCCTAT } \\
\text { R: GGCACTGACTCTTCCTTGA }\end{array}$ & 249 & NM_004176 \\
\hline apoC-I & $\begin{array}{l}\text { F: GGCTCTTCCTGTCGCTCCCGGTC } \\
\text { R: TGAGTCAATCTTGAGTTTCTCCT }\end{array}$ & 245 & NM_001645 \\
\hline GAPDH & $\begin{array}{l}\text { F: ACCACAGTCCATGCCATCAC } \\
\text { R: TCCACCACCCTGTTGCTGTA }\end{array}$ & 452 & NM_001256799 \\
\hline
\end{tabular}

Primers were synthesized by Shanghai Sangon Biological Engineering Co., Ltd. (Shanghai, China). bp, base pairs; PPAR, peroxisome proliferator-activated receptor; LXR, liver X receptor; SREBP, sterol regulatory-element binding protein; apo, apolipoprotein; GAPDH, glyceraldehyde 3-phosphate dehydrogenase; F, forward; R, reverse.

A

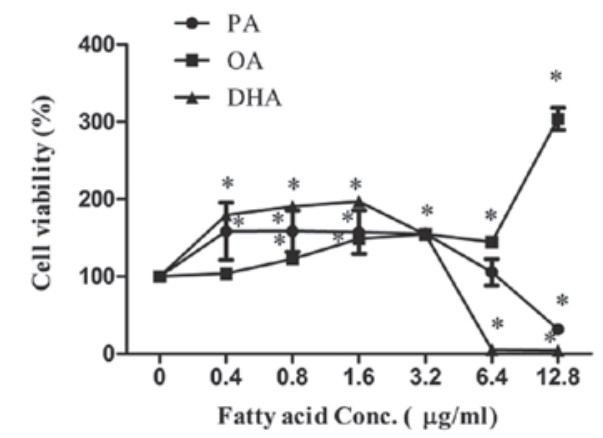

B

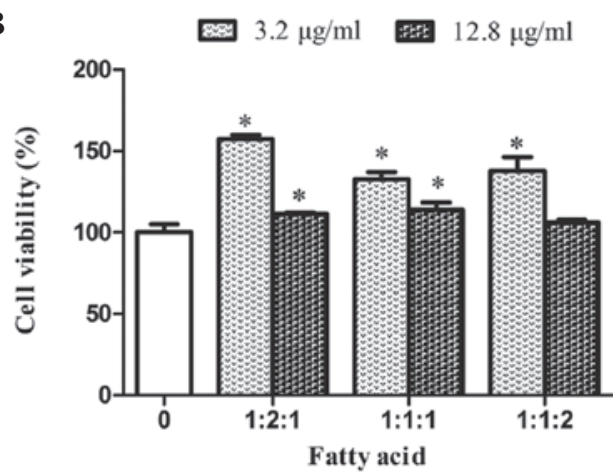

Figure 1. Effects of fatty acids on the viability of human LO2 liver cells measured using an 3-(4, 5-dimethylthiazol-2-yl)-2, 5-diphenyl tetrazolium bromide assay. (A) Cells treated with each fatty acid alone at concentrations of $0-12.8 \mu \mathrm{g} / \mathrm{ml}$. (B) Cells treated with the different ratios of fatty acids mixtures [palmitate $(\mathrm{PA})$ : oleate $(\mathrm{OA})$ : docosahexaenoic acid $(\mathrm{DHA})=1: 2: 1,1: 1: 1$ and 1:1:2, respectively]. Data were from at least three separate experiments. ${ }^{*} \mathrm{P}<0.05$, compared with the control $(0 \mu \mathrm{g} / \mathrm{ml})$ group.

expression levels were defined as the relative expression values calculated from target gene/GAPDH gene expression levels. All PCR samples were run in triplicate or quadruplicate.

Statistical analysis. Data are presented as the mean \pm standard deviation. All quantitative data represent a minimum of three experiments conducted in triplicate. Data were analyzed by one-way analysis of variance with Tamhane's T2 as a post hoc test using SPSS 17.0 statistical software (SPSS, Inc., Chicago, IL, USA). $\mathrm{P}<0.05$ was considered to indicate a statistically significant difference.

\section{Results}

Effects of FAs on LO2 cell viability. The cell viability following FA treatment was analyzed via an MTT assay and is shown in Fig. 1. At concentrations between 0 and $3.2 \mu \mathrm{g} / \mathrm{ml}$, OA increased the viability of the LO2 cells compared with the control group. DHA exhibited the same tendency at concentrations of $0-1.6 \mu \mathrm{g} / \mathrm{ml}(\mathrm{P}<0.05)$. PA significantly increased the viability of LO2 cells compared with the control group at concentrations of $0-0.4 \mu \mathrm{g} / \mathrm{ml}(\mathrm{P}<0.05)$ and maintained the same level of cell viability at concentrations of $0.4-3.2 \mu \mathrm{g} / \mathrm{ml}$. Notably, at a concentration of $3.2 \mu \mathrm{g} / \mathrm{ml}, \mathrm{OA}$, DHA and PA exhibited similar effects on cell viability $(154.9 \pm 3.7 \%$ vs. $154.4 \pm 3.7 \%$ vs. $155.6 \pm 2.5 \%$ of the control group cell viability). When the FA concentrations were $>3.2 \mu \mathrm{g} / \mathrm{ml}$, the cell viabilities of the DHA and PA groups were markedly reduced in comparison with the control group, particularly in the DHA group. No cell survived at $6.4 \mu \mathrm{g} / \mathrm{ml} \mathrm{DHA}$. However, the cell viability in the OA group was significantly increased at concentrations of 6.4-12.8 $\mu \mathrm{g} / \mathrm{ml}$ compared with the control group $(\mathrm{P}<0.05)$.

The effects of two concentrations (3.2 and $12.8 \mu \mathrm{g} / \mathrm{ml}$, as determined by the above results) of mixed FAs $(1: 2: 1$, 1:1:1 and 1:1:2 for PA:OA:DHA, respectively) on LO2 cell viability were investigated, and the results are shown in Fig. 1B. The cell viabilities following treatment with mixed FAs were all increased compared with the control $(\mu \mathrm{g} / \mathrm{ml})$ group. At $3.2 \mu \mathrm{g} / \mathrm{ml} \mathrm{FA}$, the cell viabilities of the mixed groups were similar to the single FA groups. However, at a 
A

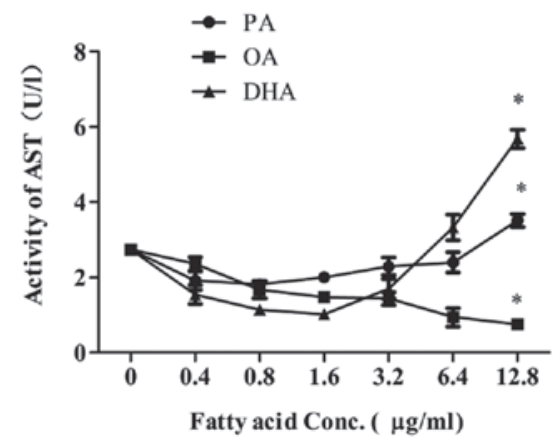

$\mathbf{B}$

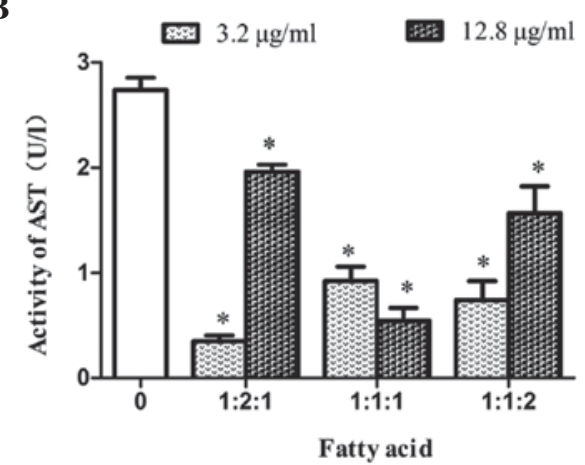

Figure 2. Effects of fatty acids on the activities of aspartate transaminase (AST) enzymes released from human LO2 liver cells. (A) Activity of AST from cells treated with single fatty acids. (B) Activity of AST from cells treated with the fatty acid mixtures [palmitate (PA): oleate (OA): docosahexaenoic acid $(\mathrm{DHA})=1: 2: 1,1: 1: 1$ and 1:1:2, respectively]. Results were repeated at least three separate experiments. ${ }^{*} \mathrm{P}<0.05$, compared with the control $(0 \mu \mathrm{g} / \mathrm{ml}) \mathrm{group}$.

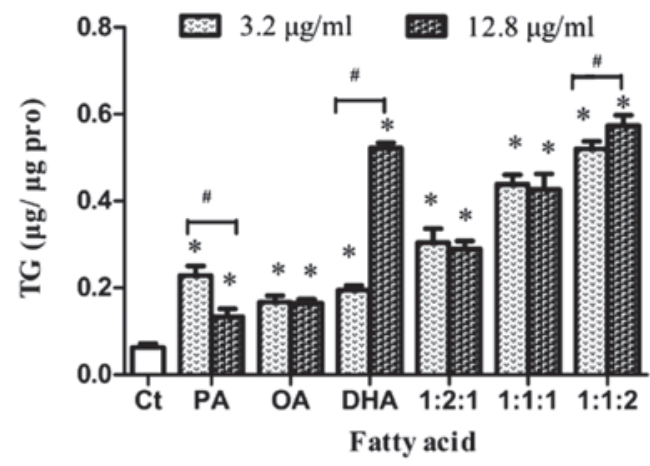

Figure 3. Effects of fatty acids (FAs) on intracellular triglyceride (TG) content in human LO2 liver cells following FA treatment. The cells were treated with single FAs or different ratios of FA mixtures [palmitate (PA): oleate $(\mathrm{OA})$ : docosahexaenoic acid $(\mathrm{DHA})=1: 2: 1,1: 1: 1$ and 1:1:2, respectively]. Results were repeated in at least three separate experiments. ${ }^{*} \mathrm{P}<0.05$, compared with the control $(0 \mu \mathrm{g} / \mathrm{ml})$ group; ${ }^{\#} \mathrm{P}<0.05$ compared with the $12.8 \mu \mathrm{g} / \mathrm{ml}$ concentration.

total FA concentration of $12.8 \mu \mathrm{g} / \mathrm{ml}$, the mixed FA-treated cells exhibited increased cell viabilities compared with PA or DHA treatment alone and reduced cell viabilities compared with OA treatment alone. However, the cell viability among the three mixed FA groups was not observed to be significantly different.

Effects of FAs on AST released from LO2 cells. The activity level of AST released from $\mathrm{LO} 2$ cells following FA treatment was detected and the results are shown in Fig. 2. OA, DHA and PA exhibited different effects on AST activity (Fig. 2A). OA dose-dependently reduced the levels of AST at increasing concentrations. DHA decreased the activity of AST at concentrations $<1.6 \mu \mathrm{g} / \mathrm{ml}$ and increased the activity of AST with concentrations $>1.6 \mu \mathrm{g} / \mathrm{ml}$. The AST activity remained constant with increasing PA concentrations until the PA concentrations reached $>6.4 \mu \mathrm{g} / \mathrm{ml}$ when the AST activity was increased significantly $(\mathrm{P}<0.05)$. When the concentrations of each FA were $<6.4 \mu \mathrm{g} / \mathrm{ml}$, the effects of PA and DHA on AST activity were not identified as significantly different. At a concentration of $12.8 \mu \mathrm{g} / \mathrm{ml}, \mathrm{PA}$ and DHA significantly increased AST activity $(\mathrm{P}<0.05)$, compared with that of the control group, whilst OA significantly decreased AST activity $(\mathrm{P}<0.05)$.
For the three mixed FA groups, AST activity was significantly reduced compared with that of the control group (Fig. 2B; P<0.05). At a concentration of $12.8 \mu \mathrm{g} / \mathrm{ml}$, the AST activity levels of three mixture groups were 1.96 \pm 0.07 (1:2:1), $0.54 \pm 0.12(1: 1: 1)$ and $1.56 \pm 0.26(1: 1: 2) \mathrm{U} / 1$ respectively, which were lower than those of cells treated with PA $(3.51 \pm 0.18)$ or DHA $(5.68 \pm 0.25)$ alone. The AST activity of the 1:2:1 and 1:1:2 groups were increased with the increase in the mixture concentration; however, in the 1:1:1 group, AST activity was greater at lower FA concentrations.

Effects of FAs on intracellular TG. The intracellular TG content in $\mathrm{LO} 2$ cells following treatment with FAs at concentrations of 3.2 and $12.8 \mu \mathrm{g} / \mathrm{ml}$ (as determined by the results of the cell viability and AST release experiments) were detected and the results are shown in Fig. 3. The TG levels of treatment groups were all significantly higher than those of the control group $(\mathrm{P}<0.05)$, particularly in the three mixture groups. Notably, the TG content following OA treatment was similar at concentrations of 3.2 and $12.8 \mu \mathrm{g} / \mathrm{ml} \mathrm{OA}$, as it was at the different FA concentrations in the 1:2:1 and 1:1:1 mixture groups. The TG content following PA treatment was significantly reduced at an increased concentration $(\mathrm{P}<0.05)$; however, $\mathrm{TG}$ levels were significantly increased at the higher concentration in the DHA group $(\mathrm{P}<0.05)$. In addition, the intracellular TG levels in the 1:1:2 group were significantly elevated at the increased FA concentration $(\mathrm{P}<0.05)$.

Effects of FAs on mRNA expression levels of the PPAR- $\gamma$, $L X R \alpha, S R E B P-1 c$ and apoC-I genes. At concentrations of $0,3.2$ and $12.8 \mu \mathrm{g} / \mathrm{ml}$, the expression levels of the $P P A R-\gamma$, $L X R \alpha, S R E B P-1 c$ and apoC-I genes in LO2 cells were examined (Fig. 4). Treatment with single PA, OA or DHA at 3.2 and $12.8 \mu \mathrm{g} / \mathrm{ml}$ concentrations significantly increased the expression levels of PPAR- $\gamma$ mRNA in LO2 cells compared with those of the control group (Fig. 4A and $\mathrm{B} ; \mathrm{P}<0.05$ ). The mixed FA treatments exerted different effects on PPAR- $\gamma$ expression levels. For the 1:2:1 group, the PPAR- $\gamma$ expression levels were significantly increased to a similar degree at 3.2 and $12.8 \mu \mathrm{g} / \mathrm{ml}$ concentrations compared with the expression levels of the control group $(\mathrm{P}<0.05)$. Notably, for the 1:1:1 group, the PPAR- $\gamma$ expression levels were significantly reduced at $3.2 \mu \mathrm{g} / \mathrm{ml} \mathrm{FA}(\mathrm{P}<0.05)$ and was significantly increased at 
A

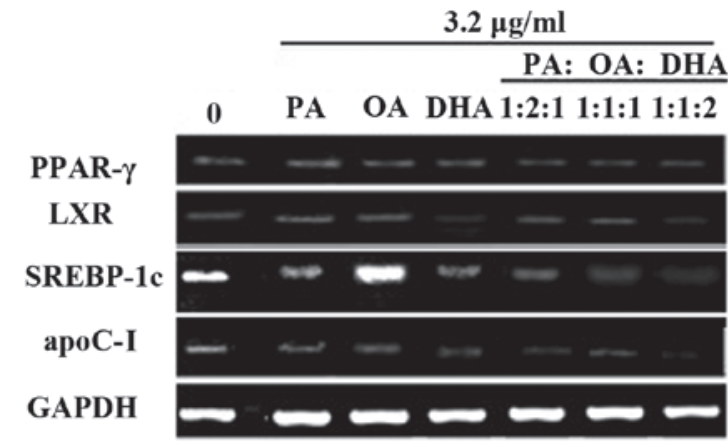

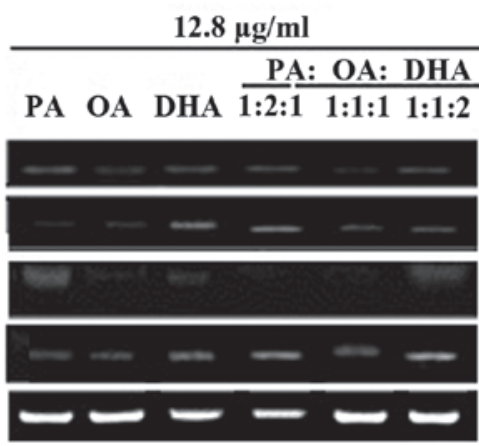

C

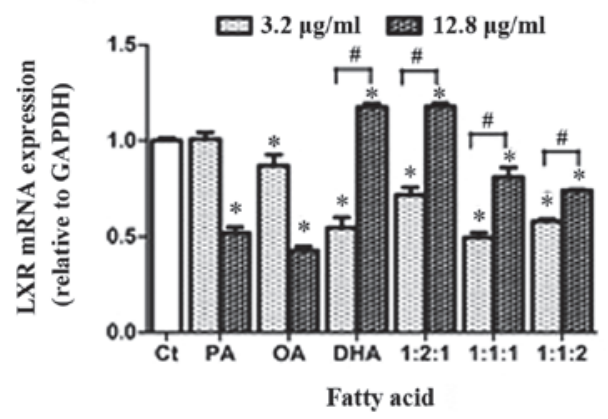

D
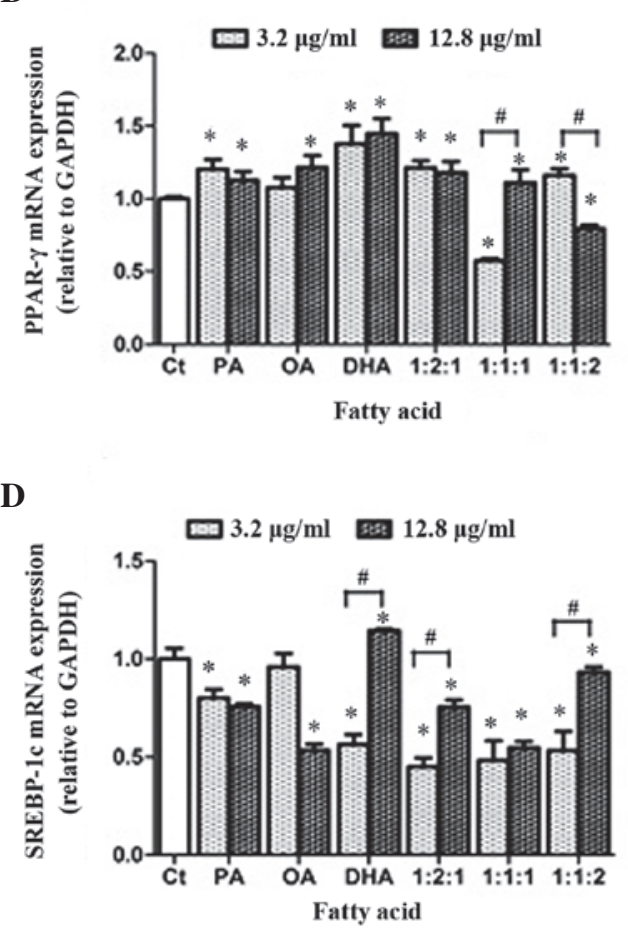

$\mathbf{E}$

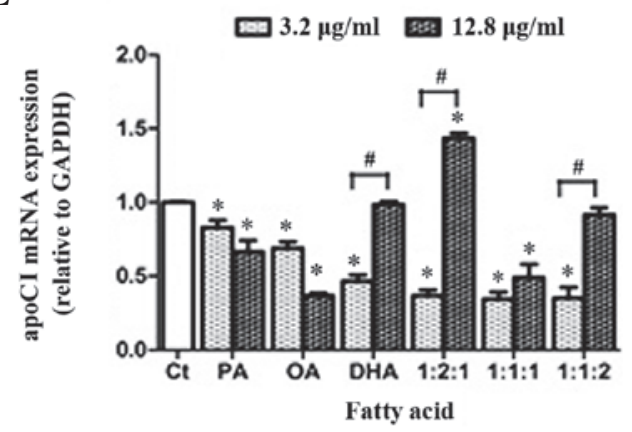

Figure 4. Effects of fatty acids (FAs) on the expression levels of peroxisome proliferator-activated receptor (PPAR)- $\gamma$, liver X receptor (LXR) $\alpha$, sterol regulatory-element binding protein (SREBP)-1c and apolipoprotein (apo)-CI genes in human LO2 liver cells. (A) Reverse transcription-polymerase chain reaction product electrophoresis. The relative expression levels of (B) PPAR- $\gamma$, (C) LXR $\alpha$, (D) SREBP-1c and (E) apoC-I in the LO2 cells following FA treatment. The GAPDH gene served as a standard. Results were repeated at least three separate experiments. ${ }^{*} \mathrm{P}<0.05$, compared with the control $(0 \mu \mathrm{g} / \mathrm{ml})$ group. ${ }^{\#} \mathrm{P}<0.05$ compared with the $12.8 \mu \mathrm{g} / \mathrm{ml}$ concentration.

$12.8 \mu \mathrm{g} / \mathrm{ml}$ compared with the expression levels of the control group. However, for the 1:1:2 group, the pattern of PPAR- $\gamma$ expression was reversed compared with that of the 1:1:1 group, with a decrease in expression at the higher FA concentration.

At a concentration of $3.2 \mu \mathrm{g} / \mathrm{ml}$, all groups, with the exception of the PA group, exhibited a significant reduction in $L X R \alpha$ expression levels compared with those of the control group (Fig. $4 \mathrm{C} ; \mathrm{P}<0.05$ ). For the $\mathrm{PA}$ and $\mathrm{OA}$ groups, the $L X R \alpha$ expression levels were also significantly reduced at the higher FA concentration, compared with the control group $(\mathrm{P}<0.05)$. For the DHA-only and 1:2:1 mixture groups, the $L X R \alpha$ expression levels after $12.8 \mu \mathrm{g} / \mathrm{ml}$ treatment were significantly increased compared with those of the control group $(\mathrm{P}<0.05)$. In addition, the 1:1:1 group exhibited a significantly increased $L X R \alpha$ expression levels at the increased FA concentration compared with the lower concentration $(\mathrm{P}<0.05)$, although the two 1:1:1 mixed FA concentrations induced significantly lower expression levels than those of the control group $(\mathrm{P}<0.05)$.
The $L X R \alpha$ expression levels in the 1:1:2 group were similar to those of the 1:1:1 group.

The expression levels of SREBP-1c in the LO2 cells following FA treatment were significantly reduced compared with those of the control group $(\mathrm{P}<0.05)$, with the exception of SREBP-1c expression levels in the $12.8 \mu \mathrm{g} / \mathrm{ml}$ DHA group, which were significantly increased in comparison with the control group (Fig. 4; $\mathrm{P}<0.05$ ). The changes in the SREBP-1c expression levels between different FA concentrations in the DHA and 1:1:2 groups were similar to the changes in $L X R \alpha$ expression levels at different FA concentrations. However, in the PA group, the SREBP-1c expression levels were similar at 3.2 and $12.8 \mu \mathrm{g} / \mathrm{ml} \mathrm{FA}$ concentrations, as were those in the 1:1:1 group. At a concentration of $3.2 \mu \mathrm{g} / \mathrm{ml} \mathrm{OA}$, the SREBP- $1 c$ expression levels were not identified as significantly different from those of the control group. The 1:2:1 group exhibited significantly increased $S R E B P-1 c$ expression levels at an increased FA concentration, compared with the lower FA 
concentration $(\mathrm{P}<0.05)$, although the two concentration of 1:2:1 mixed FAs induced significantly lower SREBP-1c expression than that of the control group $(\mathrm{P}<0.05)$.

The trend in apoC-I expression levels in single and mixed FA groups was similar to that of $L X R \alpha$ expression levels. However, compared with those of the control group, the apoC-I expression levels in the PA group were significantly reduced at 3.2 and $12.8 \mu \mathrm{g} / \mathrm{ml}(\mathrm{P}<0.05)$. Notably, the apoC-I expression levels in the DHA group were significantly elevated at the higher DHA concentration compared with the lower concentration $(\mathrm{P}<0.05)$, and the expression value at a $12.8 \mu \mathrm{g} / \mathrm{ml}$ concentration was equal to that of the control group. In the 1:1:1 group, no significant difference was identified in apoC-I expression levels between FA treatments of 3.2 and $12.8 \mu \mathrm{g} / \mathrm{ml}$.

\section{Discussion}

The results of the MTT assay and the AST activity in the present study indicated that, within a certain concentration range, the single saturated and unsaturated FAs, and the FA mixtures at different ratios increased viability and protected the integrity of LO2 cells. However, when the concentrations and/or the ratios of the FAs changed, the biological effects were varied. High doses of DHA and PA inhibited cell growth and impaired cell function, while high doses of OA exerted the opposite effects. DHA is an important biologically-active PUFA. Excess PUFA has been reported to result in the generation of lipid peroxides and potential cytotoxicity (20), indicating the importance of controlling the total level of DHA. In the mixed FA groups, the cell viabilities at $12.8 \mu \mathrm{g} / \mathrm{ml}$ were not reduced and were lower than those of cells treated with $3.2 \mu \mathrm{g} / \mathrm{ml} \mathrm{FAs}$, indicating that the higher the concentration of mixed FAs, the greater the impairment of the hepatocytes. As a saturated FA, PA effectively induces cell apoptosis compared with the mono-unsaturated OA. When the PA:OA ratio is 1:2, OA attenuates the apoptosis induced by PA (21). Similarly, the results of the present study demonstrated that OA ameliorated the inhibition of cell growth induced by high doses of PA and DHA.

In the present study, the TG levels of $\mathrm{LO} 2$ cells in the OA groups were higher than those of the control group, but were lower than those of the DHA groups. The intracellular TG level was elevated with the increased DHA level in the three mixed FA groups at either concentration (3.2 or $12.8 \mu \mathrm{g} / \mathrm{ml})$. In another study OA was found to stimulate TG synthesis and secretion, whereas DHA was observed to inhibit TG secretion (22). The effective conversion of OA into TG is considered as a protective mechanism (3).

The PPAR- $\gamma$ mRNA levels were evaluated by RT-PCR. Although $P P A R-\gamma$ normally expressed in the human and murine liver represents only $10-30 \%$ of the level in adipose tissue, obesity and over-nutrition have been shown to upregulate hepatic PPAR- $\gamma$ expression $(10,20)$. In the present study, the mRNA expression levels of PPAR- $\gamma$ in $\mathrm{LO} 2$ cells were increased following treatment with PA, OA or DHA at all concentrations. The expression levels of PPAR- $\gamma$ in the livers of mice fed on a high-fat diet have also been reported to be increased (23-25). The overactivation of $P P A R-\gamma$ may accelerate the synthesis of intracellular TG. However, the underlying mechanism is not clear, although a circulating factor has been suggested to stimulate hepatic $P P A R-\gamma$ transcription during increased energy availability. For the mixed FA groups, the PPAR- $\gamma$ expression levels were significantly reduced in the $3.2 \mu \mathrm{g} / \mathrm{ml} 1: 1: 1$ and

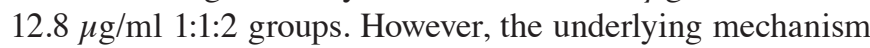
for this effect requires further investigation.

The gene encoding the nuclear receptor LXR has been cloned, and LXRs have been demonstrated to regulate cellular and systemic cholesterol homeostasis (26). Activation of PPAR $-\gamma$ has been shown to increase $L X R$ expression levels (27). The human $L X R a$ gene contains the peroxisome proliferator response element (PPRE) (28). As PPAR agonists, FAs may increase $L X R a$ expression levels. Indeed, various saturated and unsaturated FAs were demonstrated to increase LXRa expression levels in rat hepatoma cells in vitro (29). However, in the present study, the $L X R a$ expression levels were reduced to approximately half the level in the control group for several different FA treatment groups. The LXR $a$ expression levels were only significantly increased in the $12.8 \mu \mathrm{g} / \mathrm{ml}$ DHA and 1:2:1 mixed FA groups. One reason for this may be the 6-h FA treatment in LO2 cells. It has been suggested that in the short-term, FAs are LXR antagonists, whereas in the long-term, accumulation of FAs results in the upregulation of $L X R a$ gene expression (27).

SREBPS directly induced the expression of $>30$ genes involved in the synthesis and the uptake of cholesterol, FAs, TGs and phospholipids (30). Rodents fed PUFA-enriched diets manifested reduced SREBP-1c mRNA expression levels and low rates of lipogenesis in the liver (31). The results of the present study also revealed that the expression levels of $S R E B P-1 c$ mRNA in LO2 cells were significantly reduced following administration of FAs, with the exception of the $12.8 \mu \mathrm{g} / \mathrm{ml}$ DHA group, in which SREBP- $1 c$ was marginally upregulated. The reason for upregulated $S R E B P-1 c$ following DHA treatment may have been an excessive accumulation of intracellular TG. Recently, the expression levels of transcription factors involved in lipid metabolism have reported to be abnormal in the livers of obese patients with nonalcoholic fatty liver disease. The level of upregulation of $S R E B P-1 c$ was similar with that of PPAR- $\gamma$ in the livers of obese patients compared with controls (32). In addition, the induction of $P P A R-\gamma$ and SREBP- 1 is associated with the steatogenic property of FAs (21), suggesting that high doses of DHA may be associated with the steatogenic property. Alternatively, high DHA concentrations may alter cellular responses and induce a compensatory increase in SREBP-lc expression levels.

The ApoE/CI gene cluster controls the region containing the PPRE consensus sequence (the response element of $P P A R-\gamma)(14)$ and an $L X R$ response element (33). LXR agonists stimulate the expression of apoC-I, which also acts as a cholesterol acceptor (27). As an inhibitor of lipoprotein lipase, overexpression of apoC-I is associated with hypertriglyceridemia (34) and prevents the development of insulin resistance (13). In the present study, apoC-I mRNA expression levels showed a similar pattern to LXRa mRNA expression levels, suggesting that the regulation of apoC-I may be $L X R \alpha$-dependent in $\mathrm{LO} 2$ cells.

There are several limitations in the present study. Although PA, OA and DHA represented saturated, mono-unsaturated and polyunsaturated FAs, respectively, these are merely a subsection of dietary FAs. Furthermore, only one cell line was analyzed, and the only associations investigated were 
those between FAs and the expression levels of hepatic genes involved in lipid metabolism.

In conclusion, the results of the present study indicated that the type, concentration and mixture ratio of FAs are important in the regulation of cell function and expression levels of genes involved in lipid metabolism in LO2 hepatocytes and therefore provide a basis for understanding FA function in the liver.

\section{Acknowledgements}

The authors would like to thank all members of Professor $\mathrm{CH}$. Wang's laboratory (belonging to the Department of Toxicology, School of Public Health, Wuhan University, Hubei, China) for assistance and suggestions. This study was supported by the Fundamental Research Funds for the Central Universities and the National Natural Science Foundation of China (grant no. 81172628).

\section{References}

1. Dietschy JM: Dietary fatty acids and the regulation of plasma low density lipoprotein cholesterol concentrations. J Nutr 128 444S-448S, 1998.

2. Videla LA, Rodrigo R, Araya J and Poniachik J: Insulin resistance and oxidative stress interdependency in non-alcoholic fatty liver disease. Trends Mol Med 12: 555-558, 2006.

3. Aronis A, Madar Z and Tirosh O: Mechanism underlying oxidative stress-mediated lipotoxicity: exposure of J774.2 macrophages to triacylglycerols facilitates mitochondrial reactive oxygen species production and cellular necrosis. Free Radic Biol Med 38: 1221-1230, 2005.

4. McGarry JD: Banting lecture 2001: dysregulation of fatty acid metabolism in the etiology of type 2 diabetes. Diabetes 51: 7-18, 2002.

5. Zhang Y, Li R, Li Y, Chen W, Zhao S and Chen G: Vitamin A status affects obesity development and hepatic expression of key genes for fuel metabolism in Zucker fatty rats. Biochem Cell Biol 90: 548-557, 2012.

6. Chawla A, Repa JJ, Evans RM and Mangelsdorf DJ: Nuclear receptors and lipid physiology: opening the X-files. Science 294: 1866-1870, 2001.

7. Clarke SD: The multi-dimensional regulation of gene expression by fatty acids: polyunsaturated fats as nutrient sensors. Cur Opin Lipidol 15: 13-18, 2004.

8. Jump DB, Botolin D, Wang Y, Xu J, Christian B and Demeure O: Fatty acid regulation of hepatic gene transcription. J Nutr 135 2503-2506, 2005.

9. Jump DB: N-3 polyunsaturated fatty acid regulation of hepatic gene transcription. Curr Opin Lipidol 19: 242-247, 2008.

10. Boelsterli UA and Bedoucha M: Toxicological consequences of altered peroxisome proliferator-activated receptor gamma (PPARgamma) expression in the liver: insights from models of obesity and type 2 diabetes. Biochem Pharmacol 63: 1-10, 2002.

11. Schultz JR, Tu H, Luk A, et al: Role of LXRs in control of lipogenesis. Genes Dev 14: 2831-2838, 2000.

12. Repa JJ, Turley SD, Lobaccaro JA, et al: Regulation of absorption and ABC1-mediated efflux of cholesterol by RXR heterodimers. Science 289: 1524-1529, 2000.

13. Jong MC, Voshol PJ, Muurling M, et al: Protection from obesity and insulin resistance in mice overexpressing human apolipoprotein C1. Diabetes 50: 2779-2785, 2001.

14. GalettoR,AlbajarM,PolancoJI,ZakinMMandRodriguez-Rey JC: Identification of a peroxisome-proliferator-activated-receptor response element in the apolipoprotein E gene control region. Biochem J 357: 521-527, 2001.
15. Clarke SD, Jump DB: Dietary polyunsaturated fatty acid regulation of gene transcription. Annual review of nutr 14: 83-98, 1994.

16. Jump DB, Thelen A, Mater M: Dietary polyunsaturated fatty acids and hepatic gene expression. Lipids 34: S209-S212, 1999.

17. Sampath H, Ntambi JM: Regulation of gene expression by polyunsaturated fatty acids. Heart Metab 32: 32-35, 2006.

18. Pan XF, Wen CX and Xu JH: Comparison of two cell lines for cell model of hepatocytic steatosis in vitro. Journal of Guangdong Pharmaceutical College 1: 042, 2010.

19. Yang X, Zhang Y, Lin J, et al: A lower proportion of dietary saturated/monounsaturated/polyunsaturated fatty acids reduces the expression of adiponectin in rats fed a high-fat diet. Nutr Res 32: 285-291, 2012.

20. Di Nunzio M, Valli V and Bordoni A: Pro- and anti-oxidant effects of polyunsaturated fatty acid supplementation in HepG2 cells. Prostaglandins, Leukot Essent Fatty Acids 85: 121-127, 2011.

21. Ricchi M, Odoardi MR, Carulli L, et al: Differential effect of oleic and palmitic acid on lipid accumulation and apoptosis in cultured hepatocytes. J Gastroenterol Hepatol 24: 830-840, 2009.

22. Wong SH, Fisher EA and Marsh JB: Effects of eicosapentaenoic and docosahexaenoic acids on apoprotein B mRNA and secretion of very low density lipoprotein in HepG2 cells. Arteriosclerosis 9: 836-841, 1989

23. Vidal-Puig A, Jimenez-Liñan M, Lowell BB, et al: Regulation of PPAR gamma gene expression by nutrition and obesity in rodents. J Clin Invest 97: 2553-2561, 1996.

24. Knight BL, Hebbachi A, Hauton D, et al: A role for PPARalpha in the control of SREBP activity and lipid synthesis in the liver. Biochem J 389: 413-421, 2005.

25. Patel DD, Knight BL, Wiggins D, Humphreys SM and Gibbons GF: Disturbances in the normal regulation of SREBP-sensitive genes in PPAR alpha-deficient mice. J Lipid Res 42: 328-337, 2001.

26. Bensinger SJ and Tontonoz P: Integration of metabolism and inflammation by lipid-activated nuclear receptors. Nature 454: 470-477, 2008

27. Wójcicka G, Jamroz-Wiśniewska A, Horoszewicz K and Bełtowski J: Liver X receptors (LXRs). Part I: structure, function, regulation of activity, and role in lipid metabolism. Postepy Hig Med Dosw (Online) 61: 736-759, 2007.

28. Laffitte BA, Joseph SB, Walczak R, et al: Autoregulation of the human liver X receptor alpha promoter. Mol Cell Biol 21: 7558-7568, 2001.

29. Tobin KA, Steineger HH, Alberti S, et al: Cross-talk between fatty acid and cholesterol metabolism mediated by liver $\mathrm{X}$ receptor-alpha. Mol Endocrinol 14: 741-752, 2000.

30. Horton JD, Goldstein JL and Brown MS: SREBPs: activators of the complete program of cholesterol and fatty acid synthesis in the liver. J Clin Invest 109: 1125-1131, 2002.

31. Xu J, Nakamura MT, Cho HP and Clarke SD: Sterol regulatory element binding protein-1 expression is suppressed by dietary polyunsaturated fatty acids. A mechanism for the coordinate suppression of lipogenic genes by polyunsaturated fats. J Biol Chem 274: 23577-23583, 1999.

32. Pettinelli P and Videla LA: Up-regulation of PPAR-gamma mRNA expression in the liver of obese patients: an additional reinforcing lipogenic mechanism to SREBP-1c induction. J Clin Endocrinol Metab 96: 1424-1430, 2011.

33. Mak PA, Laffitte BA, Desrumaux C, et al: Regulated expression of the apolipoprotein $\mathrm{E} / \mathrm{C}-\mathrm{I} / \mathrm{C}-\mathrm{IV} / \mathrm{C}$-II gene cluster in murine and human macrophages. A critical role for nuclear liver X receptors alpha and beta. J Biol Chem 277: 31900-31908, 2002.

34. Berbée JF, van der Hoogt CC, Sundararaman D, Havekes LM and Rensen PC: Severe hypertriglyceridemia in human APOC1 transgenic mice is caused by apoC-I-induced inhibition of LPL. J Lipid Res 46: 297-306, 2005. 